\title{
CLINICAL SECTION
}

CLINICO-PATHOLOGICAL CONFERENCE-No. $3 *$

\section{Hypertension in a Young Adult}

\section{Case History (Prof. J. McMichael)}

An unmarried girl, aged 20, serving in the A.T.S., was admitted to hospital on February $2 \mathrm{I}$, 1946. She had been in the Services for three years and quite soon after joining up she noted that she was short of breath after running a short distance. After three months she reported sick. Medical examinations in the Service led to a diagnosis of an anxiety state. Palpitations and fainting attacks subsequently developed. She never had any attacks of nocturnal dyspnoea. Three months before admission to hospital she had been having severe headaches especially in the morning, and six weeks before admission she had an attack of blurred vision in one eye.

Past history. A tuberculous gland had been removed from the neck $4 \frac{1}{2}$ years previously. Apart from this there was nothing relevant.

On examination. She was a thin, rather pallid girl of cheerful disposition. B.P. was $210 / 125$; later in hospital it settled to $160 / 95$. It continued to undergo considerable spontaneous fluctuations, the lowest recorded figure being $128 / 85$. There was no abnormality in the retina. The heart was not enlarged, there were no murmurs. The urine showed an occasional trace of albumen but was usually normal; the sediment showed no abnormality. Urea clearance was 77.8 per cent. of normal. Electrocardiogram was normal.

In view of the youth of the patient every effort was made to find out whether or not any primary cause could be found for the hypertension. There was nothing to suggest coarctation of the aorta. Intravenous pyelography showed slight clubbing of the lower calyx of the right kidney. Retrograde pyelography (Fig. I) confirmed this, but it was simply regarded as an anatomical abnormality which did not justify any operative procedure. Sympathectomy was then considered and the standard tests were done. Her blood pressure did

* Held at the Postgraduate Medical School of London, Hammersmith Hospital, on February 8 1950. The Editor is most grateful to Dr. Bernard Lennox by whose care this report was assembled. The photographs are by $\mathrm{Mr}$. E. V. Willmott. not change significantly during a sedation test, and it tended to fall rather than rise with the cold pressor test. In spite of these anomalous reactions the spontaneously fluctuating character of her hypertension seemed, at that time, to hold out the hope that sympathectomy might help. Bilateral lumbo-dorsal sympathectomy (Smithwick) was completed by Mr. Franklin in July and August 1946. During the period before operation her blood pressure averaged 160/100. Following recovery and convalescence from the operation she

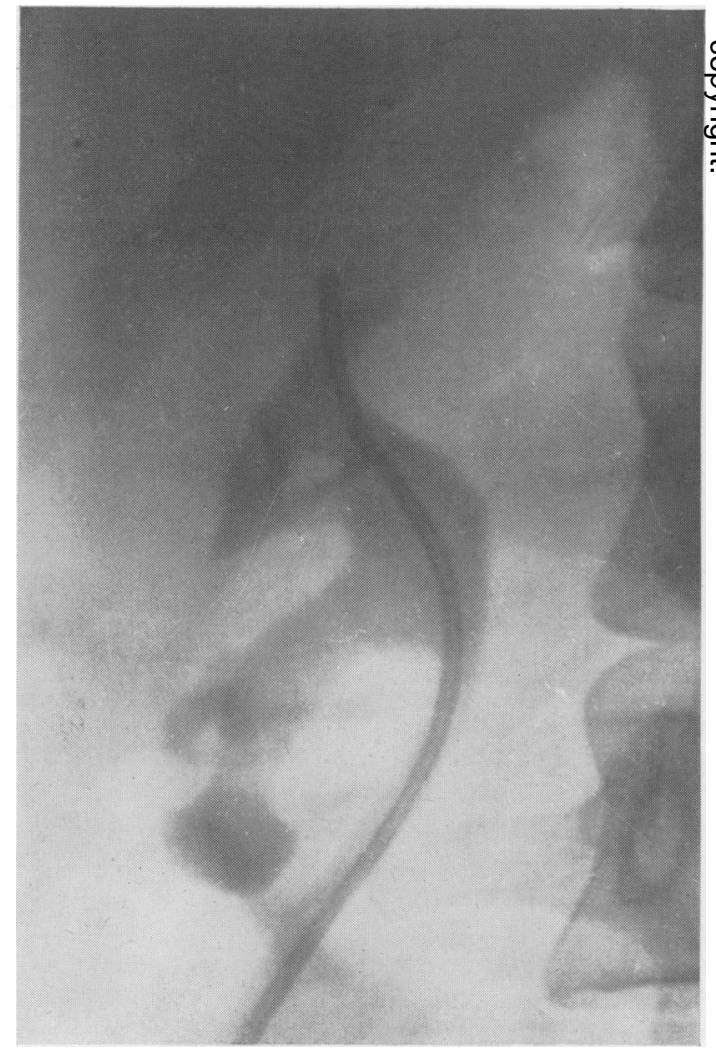

FIG. 1.-Retrograde pyelogram of the right kidney showing clubbing of the lower calyx (natural size). 
reported again in September 1946. She said she felt better and had fewer headaches, but the blood pressure was now 190/130.

Progress. From 1946 to 1948 she continued in indifferent health. Blood pressure readings in the out-patient department were usually high, the diastolic ranging from 120 to 140 and systolic from I 90 to $220 \mathrm{~mm}$. Hg. In July 1948 triple rhythm was noted on auscultation at the apex, but there was no rise in venous pressure. The urine contained albumen and an occasional granular cast. In November 1947 a few fundus haemorrhages were noted. The heart was enlarged, the apex beat being $4 \frac{1}{2}$ in. to the left of the midline in the fifth space. Urea clearance test was now 32 per cent. of normal. An effort was made to begin treatment with potassium thiocyanate but she developed a drug rash; while on the treatment her blood pressure did not change and she had two epileptiform convulsions. In December 1948 she developed a bronchitis with fever which precipitated an attack of congestive failure. She was treated with digitalis and underwent considerable symptomatic improvement so far as her dyspnoea was concerned.

In February I 949 she was admitted to hospital with ankle oedema and nocturnal dyspnoea. B.P. 210/160; heart enlarged with gallop rhythm. The fundi showed blurring of the disc edges but no haemorrhages or exudates were noted. There was some nipping of the veins at the points where the arteries crossed them. The urine contained albumen, epithelial casts, occasional leucocytes and red cells. Culture was sterile. Electrocardiogram now showed gross left ventricular preponderance. She had an anaemia with red count 2.3 million, haemoglobin $5^{8}$ per cent. (8.6 g.). Blood urea was $59 \mathrm{mg}$. per $100 \mathrm{cc}$. Creatinine clearance was $27 \mathrm{cc}$. per minute, and the effective renal plasma flow (P.A.H.) was 90 cc. per minute. This shows reduction of renal blood flow with preservation of a high glomerular filtration fraction comparable to that seen in most cases of essential hypertension. She was seen on this admission by Professor Smirk of Otago, who felt he could not accept this case as one of essential hypertension in view of her age. He thought a nephritic origin had to be considered but admitted that there was no evidence of this in the clinical history or the investigations which had been done. On this admission her left ventricular failure improved with digitalization; she was put on a salt-free, low protein diet which seemed to be accompanied by some improvement, and the blood pressure fell from $210 / 150$ on admission to $174 / 120$ on discharge.

Final admission. She was re-admitted in September 1949 orthopnoeic, with B.P. 195/130. The fundi showed no further development of the papilloedema, one or two old exudates were noted. The heart was enlarged with forceful apex. The urine specific gravity did not rise above IOI2; albumen ++ . The electrocardiogram showed left ventricular preponderance, vital capacity was 2 l., blood urea $69 \mathrm{mg}$., alkali reserve 42 volumes per roo cc. During this last admission she complained of vague generalized pains, ran a fever and leucocytosis was present in the last weeks. Drowsiness, twitching and trismus supervened. Veratrone was tried in treatment and seemed to produce temporary reduction of blood pressure but always accompanied by vomiting and malaise. Mersalyl produced considerable improvement in her heart failure. The blood urea fluctuated, rising to $160 \mathrm{mg}$. per I00 cc., but subsiding again in the following week to $68 \mathrm{mg}$. Terminally, however, the blood urea rose to $200 \mathrm{mg}$. whilst the alkali reserve fell to $\mathrm{I} 8$ volumes per $\mathrm{I} 00 \mathrm{cc}$. Pericardial friction was noted first about a month before her death, which took place on December 20, 1949.

Clinical diagnosis. It was clear that this girl had some very odd type of hypertension. It did not run the usual course of simple essential hypertension. In the last stages of her illness periarteritis nodosa was considered but there seemed to be nothing in support of this diagnosis other than fever and leucocytosis. Professor Platt (Quart. 7 . Med., 1948, 17, 83) has shown that 70 per cent.ce of cases of hypertension under the age of 40 are? secondary to some other cause-usually pyelonephritis. Perera (Amer. F. Med., 1948, 4, 416) believes, however, that essential hypertension often begins in the twenties. We though for a time that a malignant phase was developing in this patient, but she never in fact developed the full-blown picture of malignant hypertension. We therefore do not expect any arteriolonecrotic changes. We prefer to adopt in such cases the intermediate terminology of ' arteriosclerosis accelerata.' She came to autopsy therefore with the diagnosis of :-

(I) Secondary hypertension of obscure aetiology, ? periarteritis nodosa, ? obscure nephritis.

(2) Terminal ' arteriosclerosis accelerata.'

(3) Uraemic pericarditis.

Autopsy Findings (Dr. C. V. Harrison)

Externally. A rather thin young woman with well-healed scars of the sympathectomy operations.

Internally. Kidneys: The right (Fig. 2) weighed only $46 \mathrm{~g}$. (normal $=\mathrm{I} 50 \mathrm{~g}$.). The lower half was converted into a thin rind by severe scarring. The surface was contracted and the pelvis enlarged and the whole thickness here was only 6 to $7 \mathrm{~mm}$. The upper half retained a fairly normal pattern. The left kidney was used for arterial injection (Fig. 3). This showed a very 


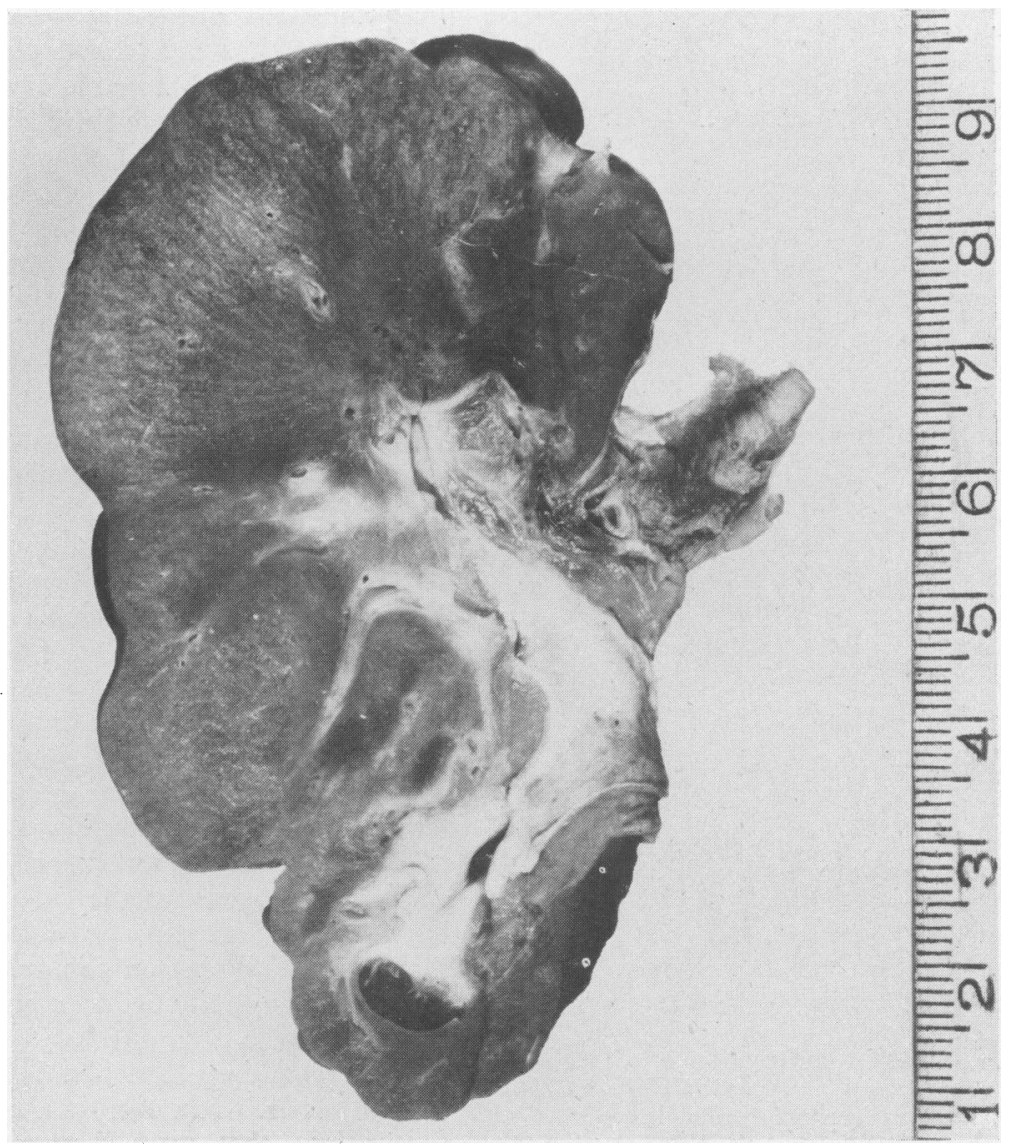

FIG. 2.-Coronal section of the right kidney showing pyelonephritic atrophy round the dilated lower calyx ( $\times$ 1.2).

closely similar general appearance but here the upper half had been destroyed. In this part the interlobular arteries were almost obliterated but in the residual unscarred half the vessels were apparently normal. The picture as a whole was diagnosed as healed pyelonephritis. Heart: There was a healed pericarditis. Heart weight $405 \mathrm{~g}$. (normal for a woman of this height $=260 \mathrm{~g}$.). This enlargement was nearly all due to left ventricular hypertrophy but there was also slight right ventricular hypertrophy. The coronary and other vessels appeared healthy and free from premature atheroma. Lungs: There was a little oedema but no other lesions. Intestinal tract: was healthy. Liver: $\left(\mathrm{I}, 59^{8} \mathrm{~g}\right.$.) was a trifle enlarged. On cutting it showed an appearance like that of an exaggerated ' nutmeg' passive congestion. This appearance, however, was not quite uniform and was at variance with the lack of passive congestion elsewhere. The portal vein, hepatic veins and hepatic artery did not show any lesion. The only other findings were a focus of heterotopic pancreas in the duodenum and an infantile uterus.

Histology. Kidney: The chronic pyelonephritis was confirmed. The vessels in this part of the kidney showed healed thrombosis and endarteritis rather than hypertensive changes. In the rest of the kidney there was very little change. The interlobular arteries showed hypertensive sclerosis and a few hyaline arterioles were found but not as many as were seen in other organs. Heart: The pericarditis and hypertrophy were confirmed. Lungs: The oedema was confirmed but there was no passive congestion. Liver: The lesion here proved to be a recent liver cell necrosis involving the central two-thirds to three-quarters of the lobules and there was severe fatty change in the surviving cells. Most of the dead cells had dis- 


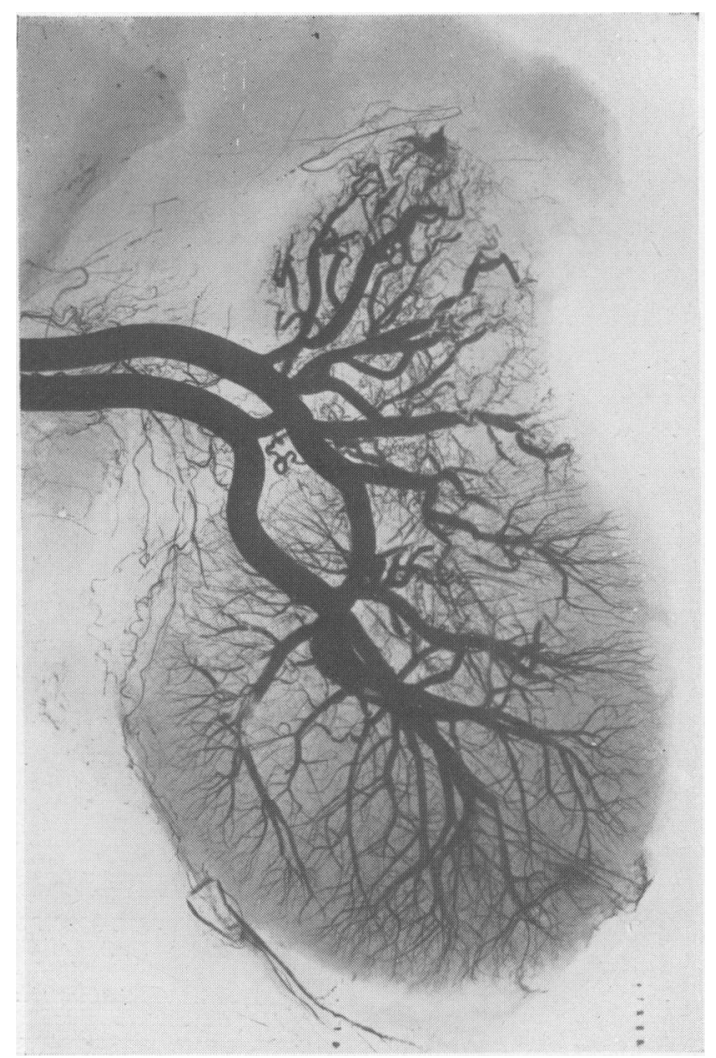

FIG. 3.-Radiograph of the left kidney after injection of an opaque mass (mercurial emulsion) into the renal artery (by Dr. C. L. Simpson). The lower half has a normal pattern, the upper half shows shortening and spiralling of the larger arteries and total loss of the brush pattern formed by the interlobular arteries. Naked eye this kidney was a reversed image of the right kidney, though the affected calyx was less dilated.

appeared leaving wide, blood-filled sinuses, but the reticulin pattern was unaltered indicating that the process was recent. This necrosis varied rather in intensity. Spleen: Did not show passive congestion but all its small arteries were hyaline. Arteries: Hypertensive, hyaline arterioles were found in the pancreas, adrenals, ovary and uterus, but none showed fibrinoid necrosis. Uterus: Showed a thin, unstimulated endometrium. Ovary: Showed normal ripening follicles.

Summary. The post-mortem findings indicated a severe hypertension due to old, healed pyelonephritis. The centrilobular liver necrosis was not due to passive congestion and could not be accounted for by any of the other findings.

\section{Discussion}

Prof. McMichael: This is an extremely interesting case and one which baffled us, as you see, in life. We always realized that there was something unusual about this patient. The reason why we failed to find the pyelonephritic origin of the hypertension was that no history of it was available and it was never active during the years she was under observation. The one way in which it might perhaps have been discovered would have been by actual inspection of the kidneys. Mr. Shackman is here and he might tell us how possible that is. I know that a good deal of renal biopsy work has been done simultaneously with lumbo-dorsal sympathectomy.

She had a diminishing pulse pressure in the later stages. It is interesting to note that she did not have the lesions of malignant hypertension with fibrinoid necrosis of the arterioles, but instead a relatively mild condition of hyaline change in the vessel walls. On the question of the liver lesion I have the impression that we see nutmeg changes in the liver more frequently in hypertension than in other types of cardiac failure.

DR. Bull: I would like to underline two points. First, the accelerated arteriosclerotic termination we see here is just one of the possible patterns of termination of hypertension of any kind. Here it occurred in hypertension of pyelonephritic origin but it could occur in almost any kind of hypertension. It can, as we know, be extremely difficult to differentiate clinically and even sometimes pathologically between an idiopathic type of hypertension on the one hand and a renal hypertension secondary to nephritis and pyelonephritis on the other. My second point is that the investigations that were done did not reveal any points which would have led us to the correct diagnosis. There is just one possible investigation which might have helped if it had been done before the sympathectomy, and that is to have estimated the filtration fraction - at a time, that is, before she actually went into cardiac failure. It is possible then that she would have shown a relatively low filtration fraction, whereas in hypertension one tends to get a high filtration fraction.

I do not think the sparing of the vessels of part of the kidney is surprising. It is perhaps the same thing as happens in a Goldblatt kidney; the kidney in which the renal artery has been constricted is spared the effects of the malignant hypertension; and in the same way the arterioles of parts of this kidney were unaffected because of the fact that the kidney blood supply was affected.

Dr. Harrison: I do not agree with the last point. The Goldblatt effect applies to the segment in which there was pyelonephritis and in which we have been able to show inflammatory changes in the arteries and thrombi. In the upper half of the kidney we have demonstrated by injection that the arterial supply is intact and absolutely free 


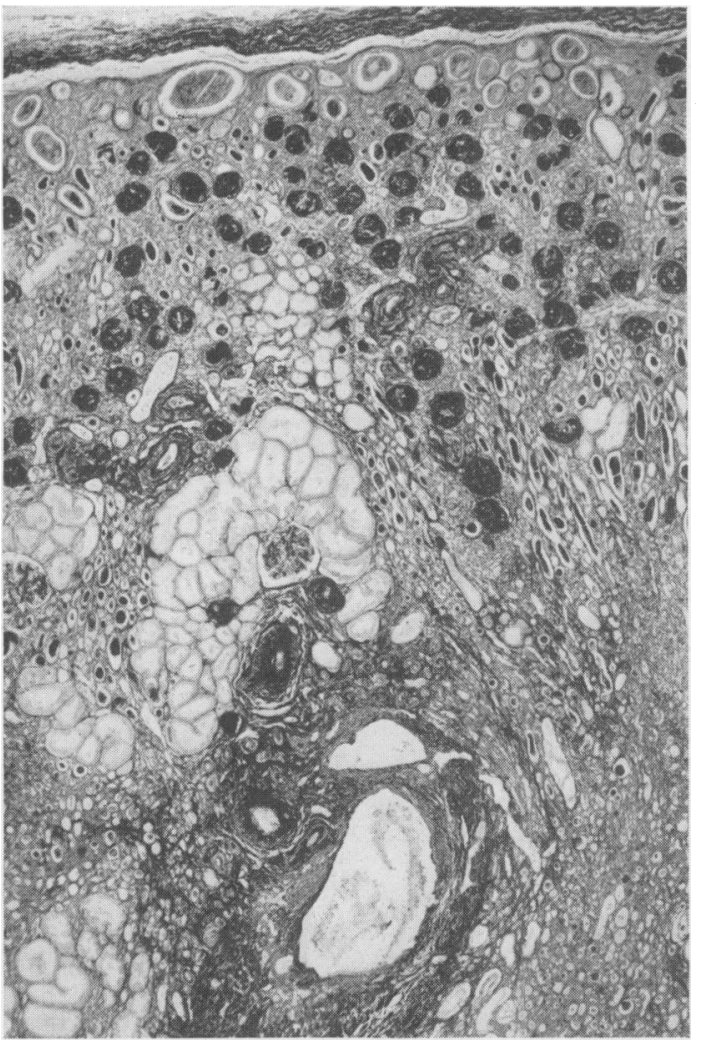

FIG. 4.-Contracted area of right kidney (picro-mallory $\times$ 33) showing the close-packed fibrosed glomeruli and, especially just under the capsule, dilated tubules full of casts. In the centre a hypertrophied nephron, and below it endarteritic arteries.

from obstruction, and there the arterioles should take the full brunt of hypertension and ought to show the defects of hypertension.

DR. BULL: If you put a cellophane capsule round the kidney that kidney is also spared the effects. That must be because you have provided a damper constriction to the whole kidney. Could it not be that in this case the whole fibrous tissue of the kidney is increased so that we imitate the effect of putting a cellophane capsule round it?

Dr. Harrison: Actually I do not think there is much fibrosis in the non-pyelonephritic portions. I believe Weiss has described sparing of the kidney in the residual parts of the pyelonephritis. Dr. Cope has just reminded me of that. So perhaps there is something in what you say, though I do not think we have any satisfactory explanation of the effect.

There is one thing I would like to take up-the question of the liver lesion. I think that we can disregard as a cause of it any vascular disturbance.
In the absence of congestive changes in other organs, and with all the main vessels patent, I cannot conceive the liver damage as being the effect of any simple vascular disturbance. Since it is a lobular lesion, it naturally raises the possibility that there was, or had been at some time in the last fortnight, a liver poison concerned, and I would like to ask what drugs or what substances injurious to the liver were given to this patient.

DR. COPE: Veratrone was given. In view of this might we know what were the indications for it and whether it could act as a liver poison?

Prof. McMichaEL: Veratrone reduces arterial pressure and in this case some therapeutic effect in this direction was achieved for a short time. Then later on the fluctuations in blood pressure became so irregular that it was abandoned and she did not have any veratrone during the last five to six weeks of her illness. I do not think there is any evidence at all that the dosage used would damage the liver.

Dr. Sherlock: Just a word about the liver. Centrilobular necrosis is a very common patho-

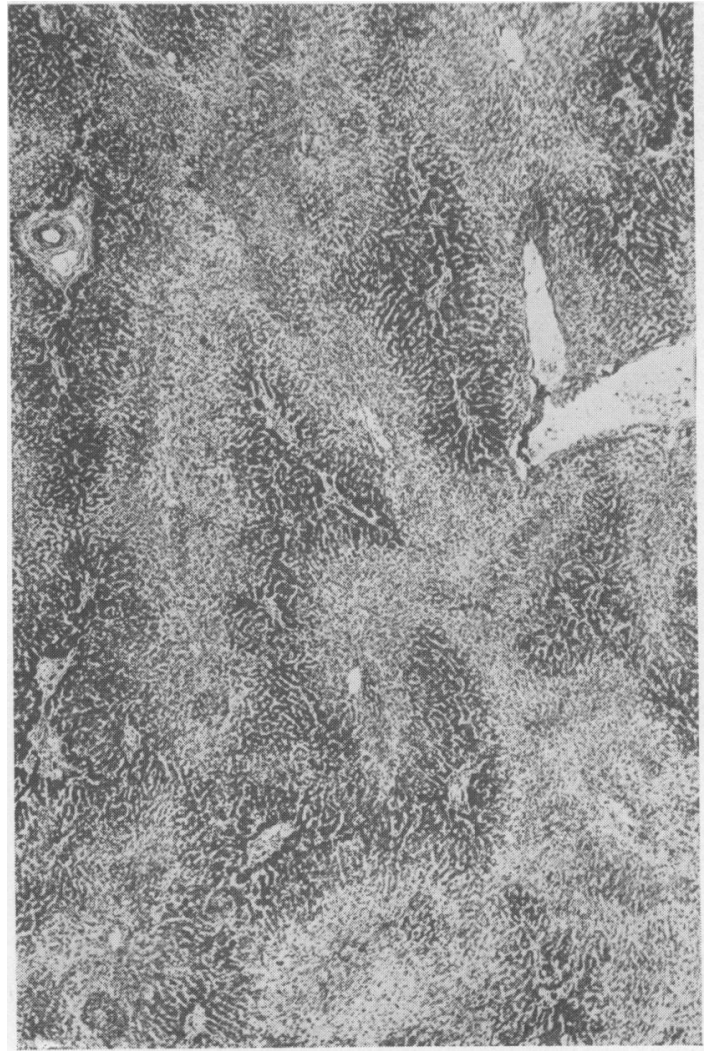

Fic. 5.-I.iver. H. \& E., $\times$ 27. Showing severe centrilobular atrophy and congestion. 
logical finding and is not specific for any one condition. The centres of the lobules receive the poorest oxygen supply and always suffer most when the liver is injured. Cardiac failure is the commonest cause of this necrosis but this has been pretty well excluded by Dr. Harrison. He has also eliminated Chiari's disease, i.e. thrombosis of the hepatic veins. Perhaps the hepatic changes can be related to other factors-starvation for instance: the patient ate very little during her last week in hospital. Histologically there was more fat in the liver than is usual in heart failure-could this be the result of malnutrition? Also, since we know the liver depends to some extent on hepatic artery blood, and this patient showed a terminal fall in pulse pressure, a lowered hepatic blood flow may have played its part.

DR. Cowen: The patient had been in cardiac failure on and off for anyhow a year and a half. Surely the liver changes could be better explained on that basis than in any other way?

Dr. Sherlock: No, I do not think so. If she had been in failure for all that time I am sure she would have had some disturbance of the hepatic reticulin framework. Answering a point Professor McMichael raised very early in this discussion, the most severe nutmeg livers are associated in our experience with mitral stenosis and tricuspid incompetence and not with hypertension.

Prof. McMichael: I can add something to Dr. Cowen's statement. This girl's cardiac failure did fluctuate in severity very considerably. Sometimes she was in failure with considerable venous engorgement and at other times she was out of failure. I think she certainly did have a sort of congestive failure during the last couple of months although the clinical picture changed as her blood pressure fell and she became more uraemic and more cachectic.

Dr. Russell Fraser: What was the cause of her terminal fever?
Prof. McMichael: I do not know. Certainly not infection. No infection was discovered at any time. I suppose it may have been a hepatic fever?

Dr. Sherlock: It could be.

DR. LENNOX: Might I ask the obvious question? If you had known that the renal lesion in the pelvis of the kidney was pyelonephritic would you have explored it, and would you have done any good if you had?

Prof. McMichael: We have had a few quite successful cases of unilateral nephrectomy where we have diagnosed unilateral disease. The most successful one was a man who had a stone in one kidney which was removed and who is alive and well and working, with a blood pressure of $120 / 70$, seven years after the operation. Before the operation he had the typical picture of malignant hypertension with a blood pressure of $250 / 150$, so it is worthwhile if you can prove the lesion is unilateral. In this case it was bilateral and I do not think we could have cured it. Could we have a surgical opinion on that?

Mr. SHACKMaN: I would certainly say that it is easy enough to explore the kidney when the sympathetic is being explored or is being operateds on for removal. I am wondering how true Professor McMichael's statement is about the possibility of nephrectomy. I believe those kidneys showed that the lower poles only were affected.

Dr. HARRISON: Lower pole in one, upper in the other.

Mr. Shackman: Partial nephrectomy is a recognized surgical manoeuvre and there is no reason at all why it should not be attempted, and in this particular case I should have thought it would have been possible to remove the lower pole in one and the upper pole in the other. 